\title{
Análise comparativa do custo de produção e da rentabilidade do cultivo de ostras (Crassostrea gigas) no verão e no inverno, em Florianópolis, SC, Brasil
}

\author{
Felipe Matarazzo Suplicy'
}

Resumo - Este artigo analisa o custo de produção de ostras cultivadas durante o verão e o inverno, para averiguar se a mortalidade de ostras associadas às elevadas temperaturas da água do mar no verão é um fator impeditivo para o cultivo nesta estação. Os resultados evidenciaram que, na fazenda acompanhada, os custos de produção foram bastante similares entre as duas estações. Os principais diferenciais encontrados na análise foram a incidência de predadores no verão e os custos mais elevados de pró-labore no inverno, devido à necessidade de um maior período de cultivo quando o ciclo é iniciado no outono. Foi recomendada uma alteração no manejo do cultivo para evitar a predação e permitir que o produtor se favoreça do período de cultivo mais curto observado no verão.

Termos para indexação: maricultura; ostras; análise econômica.

\section{Comparative analysis of production cost and profitability of oyster (Crassostrea gigas) farming in summer and winter, in Florianópolis, SC, Brazil}

\begin{abstract}
This research analyzes the producing cost of oysters grown during the summer and winter, to find out whether the mortality of oysters associated with the high temperatures of seawater in the summer is an important factor for cultivation in this season. The results showed that, on the monitored farm, production costs were quite similar between the two seasons. The main differentials found in the analysis were the higher incidence of predators in the summer and the higher costs of pro-labore in the winter, due to the need for a longer growing period when the cycle starts in the fall. A change in farm management has been recommended to avoid predation, and to allow the producer to take advantage of the shorter growing season observed in the summer.
\end{abstract}

Index terms: Marine aquaculture; oysters; economic analysis

\section{Introdução}

As ostras da espécie Crassostrea gigas são originárias de regiões com clima temperado no Oceano Pacífico, mais precisamente do Mar do Japão. Elas foram introduzidas para fins de cultivo em mais de 38 países em todos os continentes, sendo que, no Brasil, são cultivadas principalmente em Santa Catarina, com $72 \%$ da produção estadual de 2.173 toneladas concentrada em Florianópolis (EPAGRI, 2020).

As sementes de ostras Crassostrea gigas são produzidas por dois laboratórios localizados em Florianópolis, a partir de um plantel de reprodutores introduzidos no Brasil há mais de trinta anos. No começo do desenvolvimento desta atividade era comum a ocorrência de mortalidade massiva no verão, acometendo até $80 \%$ das ostras (PONTINHA, 2009). À medida que os reprodutores foram sendo selecionados entre as ostras que sobreviveram a passagem do verão, esta mortalidade foi sendo reduzida para 30 a $50 \%$, de acordo com o manejo do produtor. De maneira geral, os produtores catarinenses preferem iniciar os ciclos de cultivo no outono, para que as ostras se desenvolvam durante o inverno e estejam prontas para serem consumidas na primavera.

Apesar da ocorrência de maior mortalidade durante o verão, alguns produtores estão passando a iniciar ciclos de cultivo nesta estação para dispor de ostras de tamanho comercial durante o inverno. No entanto, a temperatura da água mais elevada e a maior ocorrência de predadores implicam em maiores riscos, com impacto direto na lucrativi- dade da fazenda (MANZONI \& SCHMITT, 2006).

Informações sobre o custo de produção no cultivo de ostras em Santa Catarina são escassas, principalmente sobre a produção durante o verão. Neste trabalho, foram analisados, de forma comparativa, o custo de produção e a lucratividade de uma fazenda de ostras localizada em Santo Antônio de Lisboa, Florianópolis, SC, durante um ciclo de cultivo iniciado no meio verão e outro no outono.

\section{Material e métodos}

A Fazenda Marinha Freguesia maneja anualmente dois milhões de sementes de ostras para produzir $100 \mathrm{mil}$ dúzias. O manejo das ostras é feito em uma balsa flutuante com $100 \mathrm{~m}^{2}$, onde

Recebido em 6/5/2020. Aceito para publicação em 13/10/2020.

${ }^{1}$ Biólogo, Ph. D., Epagri/Centro de Desenvolvimento em Aquicultura e Pesca (Cedap), Rod. Admar Gonzaga, 1188, Bairro Itacorubi, $88010-970$ Florianópolis, SC, fone: (48) 3665-5060, e-mail: felipesuplicy@epagri.gov.sc.br. 
cinco trabalhadores realizam as tarefas de classificar, ajustar a densidade das ostras, limpar e consertar os petrechos de cultivo (Figura 1). O sistema de cultivo empregado é o de travesseiros flutuantes combinado com o uso de lanternas em sistema fixo suspenso. Para avaliar o custo de produção de ostras na Fazenda Marinha Freguesia, foram acompanhados um lote de 100 mil sementes de ostras entre dezembro de 2017 e setembro de 2018 (Lote de verão), e um lote de 300 mil sementes entre março de 2019 e fevereiro de 2020 (Lote de inverno).

Para fins de comparação com outros trabalhos similares, foi empregada uma abordagem similar à utilizada por Munoz \& Mataveli (2016), em uma análise do custo de produção da ostra realizada pela Empresa Brasileira de Pesquisa Agropecuária (Embrapa), em 2015, em Santa Catarina.

A análise considerou o Custo Operacional Efetivo (COE), Custo Operacional Total (COT) e o Custo Total (CT). O COE considera os valores despendidos com a compra de sementes, gastos administrativos, impostos e taxas, combustíveis, manutenção de máquinas e equipamentos, manutenção de benfeitorias, alimentação, mão de obra contratada, além das despesas com Equipamento

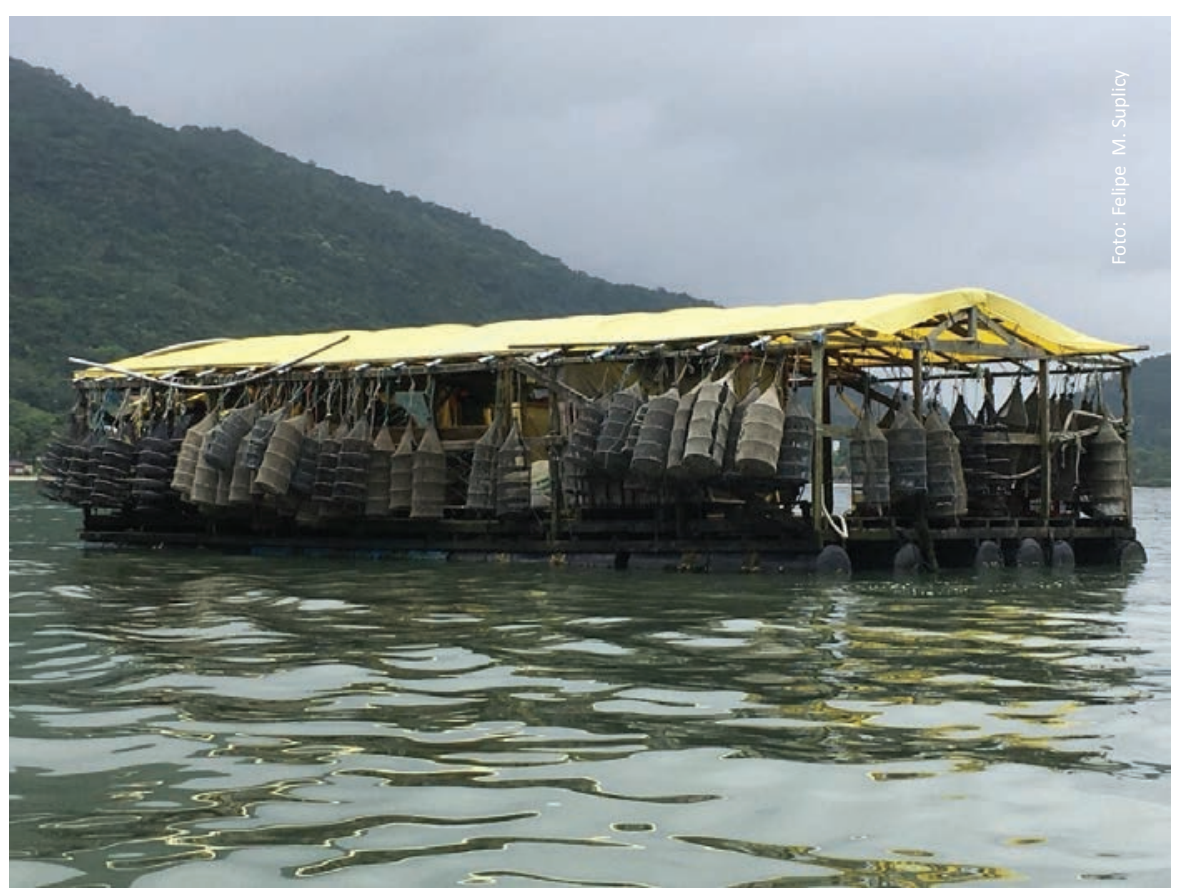

Figura 1. Aspecto externo da balsa para manejo de ostras da Fazenda Marinha Freguesia Figure 1. External aspect of the raft for handling oysters at Fazenda Marinha Freguesia de Proteção Individual (EPI). O COT considera os valores do COE, adicionados da depreciação de benfeitorias, máquinas, implementos e equipamentos e os pró-labores dos dois proprietários.

O custo da mão de obra foi calculado considerando o tempo e o esforço despendidos no manejo dos lotes de ostras, através do registro das horas e multiplicando-as pelo número de pessoas envolvidas no manejo dos lotes (hora-homem). As horas-homem foram multiplicadas pelo custo médio pago por hora aos empregados, incluindo encargos trabalhistas. A despesa com o pró-labore mensal dos proprietários da fazenda foi calculada com base na duração total de cada ciclo acompanhado, e sua proporcional participação percentual considerando o volume do lote em questão e os 2 milhões de sementes manejadas por ano na fazenda (Lote de verão $=5 \%$; Lote de inverno $=15 \%$ ).

A mesma lógica de proporcionalidade dos lotes com o volume total da fazenda foi adotada para cálculo do custo de depreciação e manutenção da balsa, do rancho, da embarcação, motores e demais equipamentos de cultivo. O custo da energia para operação da motobomba foi calculado anotando-se o tempo de lavação dos equipamentos e considerando o consumo de um litro de óleo diesel por hora. A despesa com combustível foi calculada com base no consumo médio de seis litros de gasolina hora-1 do motor de popa de $15 \mathrm{HP}$, e considerando uma hora de uso nos dias em que os lotes em questão foram manejados. Gastos administrativos, impostos e taxas consideraram a incidência de $9 \%$ sobre o lucro bruto. O rancho da fazenda é livre da cobrança de Imposto sobre a Propriedade Predial e Territorial Urbana (IPTU). A fazenda também é isenta da cobrança da taxa de Guia de Trânsito Animal (GTA), porque a unidade de processamento é localizada no mesmo endereço.

Ao final do ciclo, foram contabilizadas quantas dúzias de ostras foram produzidas para calcular a taxa de sobrevivência final, o custo de produção total, o custo de produção por dúzia de ostra e a margem de lucro da fazenda nos ciclos de verão e de inverno. Os componentes do custo de produção foram submetidos a uma análise de sensibilidade para identificar quais deles poderiam impactar mais fortemente o custo total caso ocorra um aumento de $20 \%$ ou $40 \%$ no custo do componente. A receita bruta da fazenda foi calculada multiplicando a quantidade de dúzias vendidas pelo preço de venda praticado pelo produtor, que é de $R \$ 8,00 d z^{-1}$.

\section{Resultados e discussão}

\section{Produtividade dos lotes de ostras no} verão e no inverno

O lote de verão foi seriamente afetado pelo ataque de predadores. Com dois meses de cultivo, as ostras juvenis acondicionadas em travesseiros flutuantes com malha de $9 \mathrm{~mm}$ ficaram com o umbo para fora da tela e foram intensamente predadas, provavelmente por baiacus (Sphoeroides spengleri) observados diariamente no local, resultando em uma mortalidade de $58 \%$ das ostras que estavam acondicionadas estocadas em travesseiros (Figura 2). A mortalidade acumulada até o início da colheita foi de $61 \%$, e outros $10,6 \%$ das ostras morreram naturalmente até que as todas as sobreviventes atingissem o tamanho de colheita. As primeiras ostras foram coIhidas a partir dos 160 dias de cultivo. A colheita se estendeu por mais 162 dias, - 
totalizando um ciclo de 322 dias com 40 dias de manejo do lote. Foram consumidas 303 horas-homem para a produção de 2.398 dúzias, com uma sobrevivência de $28,4 \%$.

O lote de inverno não foi afetado por predações expressivas como o lote de verão. As ostras $C$. gigas, originárias do Pacífico e adaptadas à água fria, apresentaram um crescimento mais rápido do que o lote de verão, com as primeiras ostras atingindo o tamanho comercial após 122 dias. A colheita se estendeu por mais 238 dias, totalizando um ciclo de 360 dias com 50 dias de manejo do lote. Foram consumidas 1.010 horashomem para obter uma produção de 9.143 dúzias, com uma sobrevivência de $36,6 \%$.

Custo de produção dos lotes de ostras no verão e no inverno

Os componentes do custo de produção e a margem de lucro de cada lote são apresentados na Tabela 1. Em ambos os lotes, o COE representa cerca de $60 \%$ do CT. Os demais $40 \%$ são compostos pelas despesas com depreciação, pró-labore e remuneração do capital. No verão, a renda bruta foi superior ao COE. No entanto, quando incluídas as despesas com depreciação, pró-labore e remuneração do capital, a margem ficou negativa. No inverno, a renda bruta foi superior ao $\mathrm{CT}$, resultando em uma margem de $\mathrm{R} \$ 7.200,00$. As ostras produzidas no verão tiveram um custo de $\mathrm{R} \$ 9,04 \mathrm{dz}^{-1}$. e as ostras produzidas no inverno tiveram um custo de produção de $R \$ 7,21 d z^{-1}$. A margem bruta unitária foi de $-R \$ 1,04 d z^{-1}$. no verão e de $R \$$ $0,80 \mathrm{dz}^{-1}$. no inverno.

A contribuição percentual dos componentes do custo de produção dos dois lotes é apresentada na Figura 3. A mão de obra foi o componente com maior participação nos dois lotes (34\%), seguido das despesas com pró-labore e aquisição das sementes.

Uma análise da sensibilidade do custo de produção para variações percentuais em seus principais componentes mostra que ambos os lotes foram mais sensíveis à variação no custo de mão de obra, seguida pelas despesas com prólabore e aquisição das sementes (Figura 4).

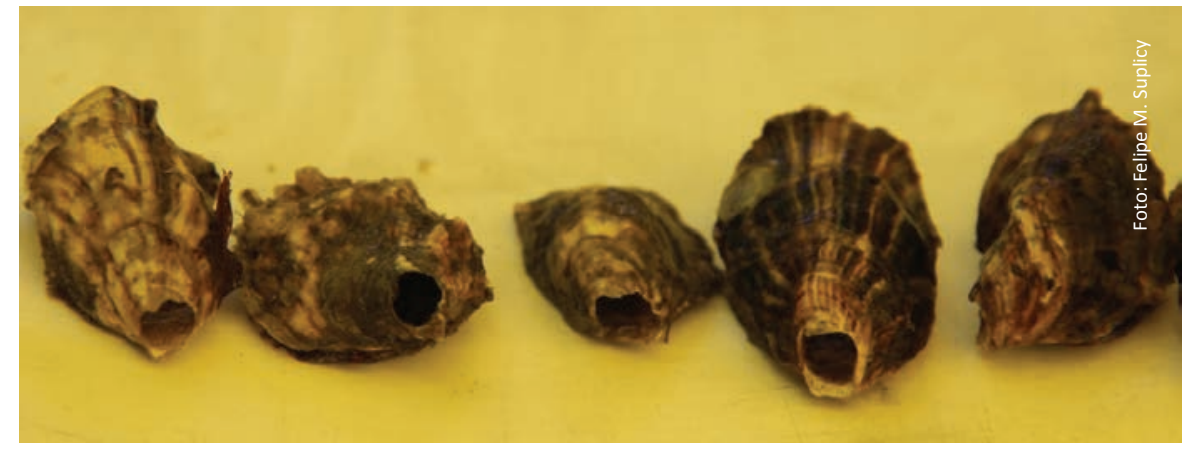

Figura 2. Ostras juvenis predadas por baiacu, durante o cultivo nos meses de verão Figure 2. Juvenile oysters preyed on puffer fish during cultivation in the summer months

Tabela 1. Componentes do custo de produção dos ciclos de cultivo de ostras no verão e no inverno

Table 1 Components of the oyster production cost for the farming cycles in summer and winter

\begin{tabular}{|c|c|c|c|c|}
\hline & \multicolumn{2}{|c|}{ Lote de Verão } & \multicolumn{2}{|c|}{ Lote de Inverno } \\
\hline & $\begin{array}{c}\text { Valor por lote } \\
\text { (R\$) }\end{array}$ & $\begin{array}{l}\text { Valor por } \\
\text { dúzia (R\$̦) }\end{array}$ & $\begin{array}{l}\text { Valor por lote } \\
\text { (R\$) }\end{array}$ & $\begin{array}{l}\text { Valor por } \\
\text { dúzia }(R \$)\end{array}$ \\
\hline 1. Renda Bruta & $19.184,00$ & 8,00 & $73.144,00$ & 8,00 \\
\hline \multicolumn{5}{|l|}{ 2. Custo de Produção } \\
\hline \multicolumn{5}{|l|}{ 2.1 Custo Operacional Efetivo - COE } \\
\hline Sementes & $2.200,00$ & 0,92 & $6.600,00$ & 0,72 \\
\hline $\begin{array}{l}\text { Gastos administrativos, impostos e } \\
\text { taxas }\end{array}$ & $1.726,56$ & 0,72 & $6.582,96$ & 0,72 \\
\hline Energia e combustível & $1.205,40$ & 0,50 & $1.580,76$ & 0,17 \\
\hline $\begin{array}{l}\text { Manutenção - Máquinas e } \\
\text { equipamentos }\end{array}$ & 107,65 & 0,04 & 283,03 & 0,03 \\
\hline Manutenção - Benfeitorias & 21,16 & 0,01 & 70,98 & 0,01 \\
\hline Mão de obra contratada & $7.280,24$ & 3,04 & $22.570,30$ & 2,47 \\
\hline EPI & 503,10 & 0,21 & $1.509,30$ & 0,17 \\
\hline COE total & $13.044,11$ & 5,44 & $39.197,34$ & 4,29 \\
\hline \multicolumn{5}{|l|}{ 2.2 Custo Operacional Total - COT } \\
\hline Custo Operacional Efetivo & $13.044,11$ & 5,44 & $39.197,34$ & 4,29 \\
\hline Depreciação - Benfeitorias & 370,30 & 0,15 & 591,50 & 0,06 \\
\hline $\begin{array}{l}\text { Depreciação - Máquinas e } \\
\text { equipamentos }\end{array}$ & $1.013,92$ & 0,42 & $3.401,13$ & 0,37 \\
\hline Pró-labore & $5.251,50$ & 2,19 & $17.615,87$ & 1,93 \\
\hline COT total & $19.679,83$ & 8,21 & $60.805,83$ & 6,65 \\
\hline \multicolumn{5}{|l|}{ 2.3 Custo Total - CT } \\
\hline Custo Operacional Total & $19.679,83$ & 8,21 & $60.805,83$ & 6,65 \\
\hline Remuneração de capital - Benfeitorias & 444,36 & 0,19 & 709,80 & 0,08 \\
\hline $\begin{array}{l}\text { Remuneração de capital - Máquinas e } \\
\text { equipamentos }\end{array}$ & $1.552,62$ & 0,65 & $4.427,38$ & 0,48 \\
\hline CT total & $21.676,80$ & 9,04 & $65.943,01$ & 7,21 \\
\hline 3. Margem bruta & $-2.492,80$ & & $7.200,99$ & \\
\hline
\end{tabular}



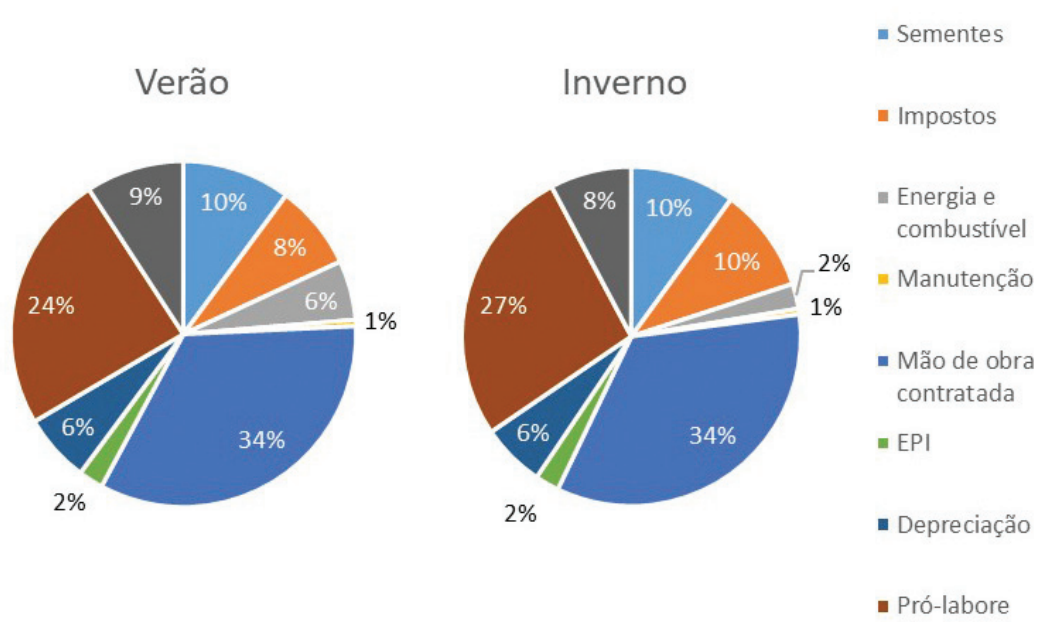

Figura 3. Contribuição percentual dos componentes do custo de produção para os lotes de ostras produzidos no verão e no inverno

Figure 3. Percentage contribution of the production cost components for the oyster batches produced in summer and winter

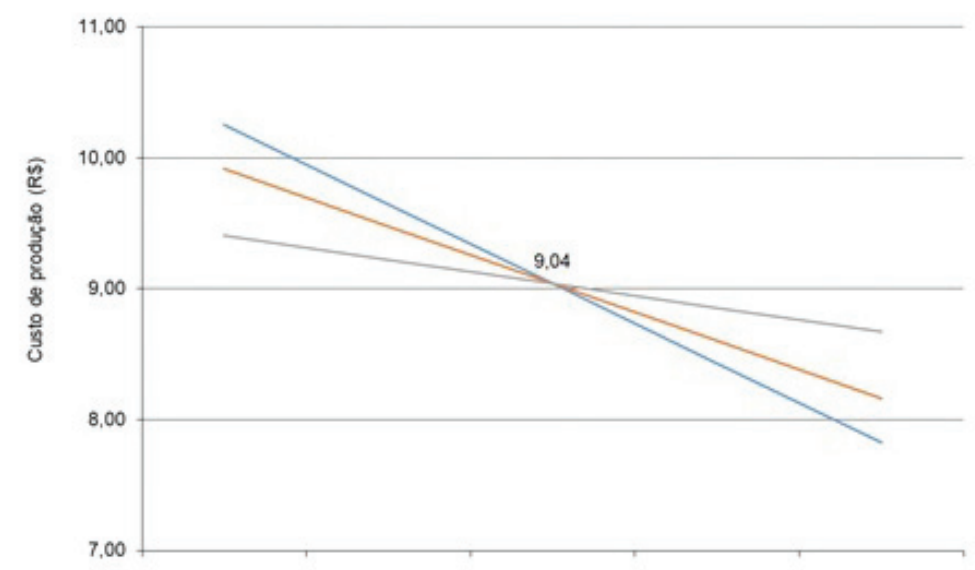

A

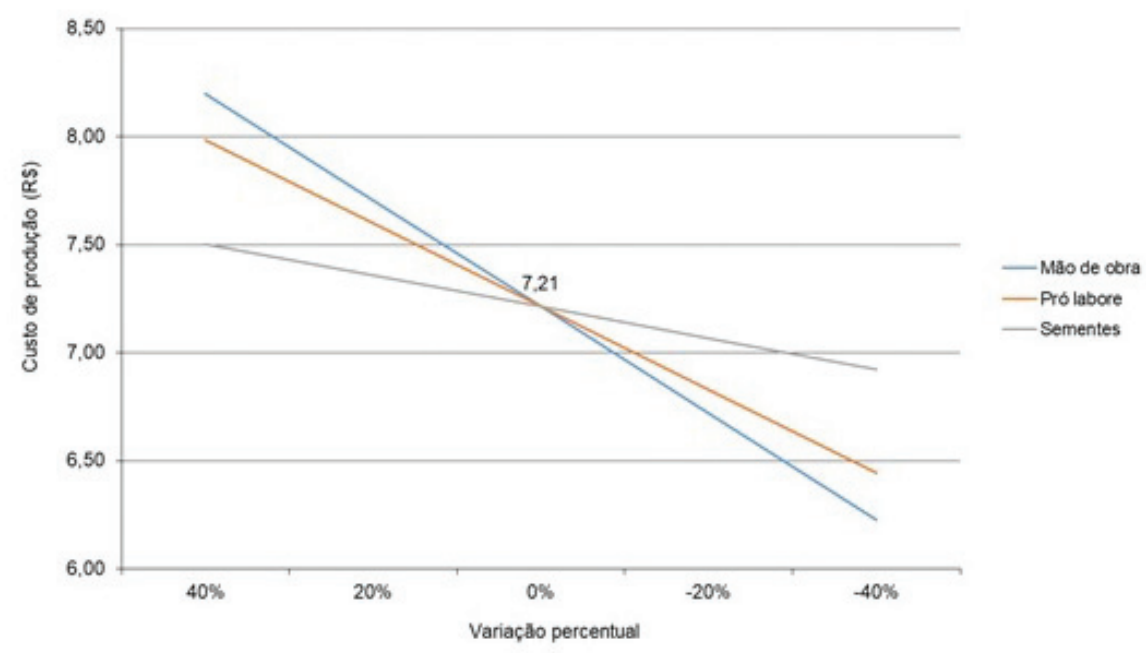

Figura 4. Análise de sensibilidade do custo de produção da ostra às variações percentuais no custo da mão de obra, pró-labore e sementes. (A) Inverno e (B) Verão

Figure 4. Sensitivity analysis of the oyster production cost to percentage changes in the cost of labor, pro-labore and seeds. (A) Winter and (B) Summer
Além da mortalidade normalmente associada à temperatura mais elevada da água do mar (SÜHNEL et al. 2017), o lote de verão também foi fortemente afetado pela predação de ostras juvenis. A vantagem de um ciclo de cultivo mais curto proporcionado pelas temperaturas mais altas do verão, com impacto direto na redução de componente importante do CT como o pró-labore, foi anulada pela predação das ostras. $\mathrm{O}$ ciclo mais longo de inverno resultou em uma participação maior do pró-labore, que contribuiu com $27 \%$ do CT, em comparação com $24 \%$ observado no lote de verão. Para atingir o ponto de equilíbrio, ou o momento em que a receita e as despesas totais se tornam equivalentes e não há prejuízos nem lucro para a empresa, o lote de verão precisaria atingir uma sobrevivência de pelo menos $37,8 \%$. Por outro lado, o ponto de equilíbrio do lote de inverno poderia ser atingido com uma sobrevivência de apenas $32 \%$.

Um aspecto que deve ser considerado nesta análise é o baixo preço pago pela ostra no mercado catarinense, em comparação com os preços praticados em outros países produtores como Estados Unidos (US\$13,00 dz $z^{-1}$ ), França (EU\$ 7,30 $\mathrm{dz}^{-1}$.) e Austrália (US\$ 6,38 $\mathrm{dz}^{-1}$.) onde as ostras são valorizadas como uma iguaria (HUDSON, 2019; STATISTA, 2020; DPI, 2018). O problema do baixo preço de venda já havia sido identificado como uma ameaça à manutenção da atividade no levantamento de custo de produção realizado pela Embrapa em 2015, quando as ostras eram vendidas por $\mathrm{R} \$ 5,00 \mathrm{dz}^{-1}$. (MUNOZ \& MATAVELI, 2016). Um fator que dificulta uma melhor valorização das ostras é a competição interna que existe no setor, em particular entre as ostras com e sem inspeção sanitária, uma vez que as ostras sem inspeção são vendidas a preços inferiores. Outro aspecto que influencia o preço de venda é o fato de que a grande maioria dos produtores não registra as despesas realizadas durante o processo produtivo, principalmente as despesas com mão de obra familiar e não assalariada, levando-os, muitas vezes, a vender o produto por um preço abaixo de seu custo de produção.

As despesas com mão de obra, o principal componente de custo, po-॰ 
deriam ser reduzidas substancialmente com a adoção da mecanização nos processos de classificação e seleção. 0 investimento na aquisição de uma classificadora mecânica poderia contribuir para a fazenda obter ganhos de escala, na qual o aumento na produção não viria acompanhado de um aumento proporcional no custo, fazendo com que o custo médio seja mais barato e assim gerando redução de custos e aumento da lucratividade. É recomendável que nos ciclos iniciados no verão as ostras juvenis sejam mantidas em uma estrutura com abertura de malha menor do que $9 \mathrm{~mm}$.

\section{Conclusão}

- O pró-labore é um componente importante do custo de produção nesta fazenda;

- Cultivar as ostras no verão pode ser economicamente interessante se as perdas por predação puderem ser controladas com um ajuste no manejo.

\section{Agradecimentos}

O autor agradece à Leonardo Costa Cabral e a toda equipe da Fazenda Marinha Freguesia pelo apoio indispensável para a condução desta pesquisa.

\section{Referências}

DPI. Provisional Aquaculture Production Report 2017-2018. Department of Primary Industries. Disponível em:https:// www.dpi.nsw.gov.au/_data/assets/pdf_ file/0020/844400/Provisional-ProductionReport-2017-2018. Acesso em: 05 mai. 2020.

EPAGRI. Infoagro. Disponível em: http:// www.infoagro.sc.gov.br/index.php/safra/ producao-animal. Acesso em: 20 fev. 2020.

HUDSON, K., VIRGINIA SEA GRANT MARINE ADVISORY PROGRAM. Virginia Shellfish Aquaculture Situation and Outlook Report: Results of the 2018 Virginia Shellfish Aquaculture Crop Reporting Survey. Marine Resource Report No. 2019-8; Virginia Sea Grant VSG-19-03. Virginia Institute of Marine Science, William \& Mary. DOI: https:// doi.org/10.25773/jc19-y847.

MALLET, A. L.; CARVER, C. E.; DOIRON, S.; THÉRIAULT, M. H. Growth performance of Eastern oysters Crassostrea virginica in Atlantic Canada: Effect of culture gear. Aquaculture, Amsterdã, v. 396-399, p.1-7. 2013. DOI: https://doi.org/10.1016/j.aquaculture.2013.02.019.

MANZONI, G. C.; SCHMITT, J. F. Cultivo de ostras japonesas Crassostrea gigas (Mollusca: Bivalvia), na Armação do Itapocoroy, Penha, SC. In: BRANCO, O. J.\& MARENZI, A. W. C. (Eds.) Bases ecológicas para um desenvolvimento sustentável: estudos de caso em
Penha, SC. Projeto Aves Marinhas, UNIVALI, 2006. p.245-252.

MUNOZ, A.E.P, MATAVELI, M. Ostreicultores e técnicos discutem os custos de produção de ostras em Florianópolis - SC. Informativo Campo Futuro, n.27. Embrapa, Palmas, TO. 2016.

PONTINHA, V.A. Diagnóstico da saúde da ostra Crassostrea gigas (Thunberg, 1793) cultivada em Florianópolis/SC. Dissertação (Mestrado em Aquicultura) - Centro de Ciências Agrárias, Universidade Federal de Santa Catarina, Florianópolis, SC, 2009.

STATISTA. Fresh oysters average price in France from 2014 to 2018. Disponível em: https://www.statista.com/statistics/1007354/average-price-of-fresh-oysters-france/\#: :text=Average\%20price\%20 of\%20fresh\%20oysters\%20in\%20France\%20 2014\%2D2018\&text $=\ln \% 202018 \% 2$ C\%20 the $\% 20$ average $\% 20$ price $\% 20$ of $\% 20$ fresh\%20oysters\%20reached\%207.3\%20euros.. Acesso em: 09 set. 2020.

SÜHNEL, S.; PICANÇO, T.; MEDEIROS, S.C.; MAGALHÃES, A.R.M.; MELO, C.M.R. Effects of seeding date and seed size on Crassostrea gigas (Thunberg, 1793) culture in a subtropical climate. Journal of Shellfish Research, Groton, CT, v.36, n.2, p.303-313, 2017. DOI: https://doi.org/10.2983/035.036.0202.

\section{Siga a Epagri nos redes socialis}
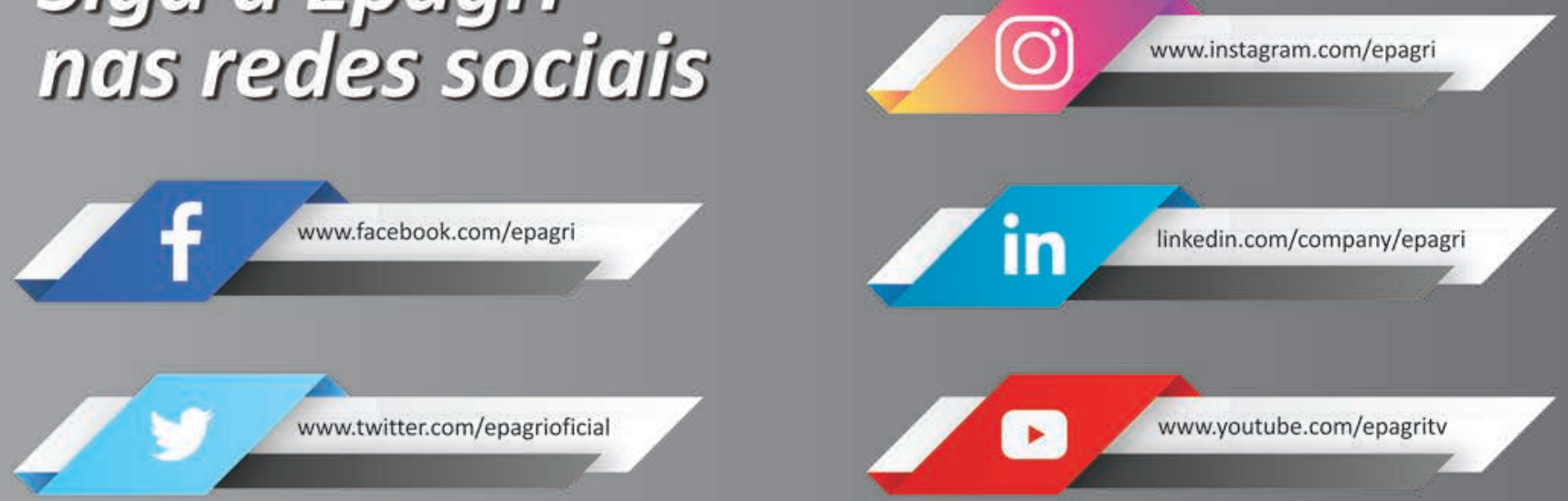